\title{
Blood pressure variability assessed by home measurements: a systematic review
}

\author{
George S Stergiou ${ }^{1}$, Angeliki Ntineri ${ }^{1}$, Anastasios Kollias ${ }^{1}$, Takayoshi Ohkubo ${ }^{2}$, Yutaka Imai ${ }^{3}$ and \\ Gianfranco Parati ${ }^{4,5}$
}

Accumulating evidence suggests that day-by-day blood pressure (BP) variability assessed using self-measurements by patients at home (HBPV) provides useful information beyond that of average home BP. This systematic review summarizes the current evidence on day-by-day HBPV. A systematic literature search (PubMed) revealed 22 eligible articles. Independent prognostic value of day-by-day HBPV for cardiovascular events and total mortality was demonstrated in two outcome studies, whereas novel indices of variability had minimal or no independent prognostic ability. Although findings are not consistent among the studies, the evidence suggests that HBPV has an independent role in the progression of preclinical cardiac, arterial and renal damage and is affected by age, gender, average BP and heart rate level, antihypertensive treatment, antihypertensive drug class and other factors. However, there is large diversity among the available studies in the home BP monitoring protocols, the indices used to quantify HBPV and the end points selected for evaluation. Overall, these preliminary data largely based on heterogeneous studies indicate an important and independent role of day-by-day HBPV in the pathogenesis of hypertensioninduced cardiovascular damage. Yet, fundamental questions remain unanswered, including the optimal variability index, the optimal home monitoring schedule required, the threshold that defines increased HBPV and the impact of treatment-induced variability change on organ damage and cardiovascular events. Until these questions are adequately addressed in future studies, HBPV should largely remain a research issue with limited practical value for individual patients.

Hypertension Research (2014) 37, 565-572; doi:10.1038/hr.2014.2; published online 20 February 2014

Keywords: cardiovascular prognosis; home blood pressure; self-measurement; target organ damage; variability

\section{INTRODUCTION}

Accumulating evidence suggests that increased variability of blood pressure (BP) exerts additional stress on the cardiovascular system independent of its average value, resulting in increased risk of target organ damage and cardiovascular events.

The clinical relevance of BP variability was first demonstrated by assessing $24-h$ beat-to-beat variability using intra-arterial monitoring. ${ }^{1}$ More recent studies showed that non-invasive intermittent reading-to-reading $24-\mathrm{h}$ ambulatory $\mathrm{BP}$ variability also provides additional prognostic information beyond that of average ambulatory BP. ${ }^{2}$ Moreover, retrospective analyses of outcome studies demonstrated that visit-to-visit systolic BP variability assessed by repeated measurements in office visits is a strong predictor of stroke independent of the average BP. ${ }^{3-5}$ Finally, day-to-day BP variability based on self-home BP measurements has also been shown to provide independent prognostic information beyond that of average home BP (HBP). ${ }^{6}$

Despite the fact that reading-to-reading, visit-to-visit and day-today BP variability assessed by ambulatory, office and home measurements, respectively, have all been shown to predict cardiovascular event risk, they probably represent different components of BP variability, may reflect different mechanisms, are likely to provide different information on cardiovascular regulation and might have different clinical implications that are still poorly understood. $^{7}$

Self-home BP monitoring is widely available in several countries and is well accepted by hypertensive patients. ${ }^{8}$ Thus, it has been suggested that in clinical practice, the assessment of BP variability by self-home measurements (HBPV) might be more feasible as well as more reliable and cost-effective than office or ambulatory BP variability measurements and more appropriate for repeated assessment in the long-term follow-up of treated hypertension. ${ }^{9}$

The objective of this paper is to perform a systematic review of the evidence on HBPV and, especially, to present data on the methodology applied for its evaluation and its clinical prognostic relevance. Moreover, the strengths and weaknesses of current research on HBPV are summarized, together with the remaining research questions and the potential for clinical application.

${ }^{1}$ Hypertension Center, STRIDE Hellas-7, Third Department of Medicine, University of Athens, Sotiria Hospital, Athens, Greece; ${ }^{2}$ Teikyo University School of Medicine, Tokyo, Japan; ${ }^{3}$ Tohoku University Graduate School of Pharmaceutical Sciences, Sendai, Japan; ${ }^{4}$ Department of Health Sciences, University of Milano-Bicocca, Milan, Italy and ${ }^{5}$ Department of Cardiology, S. Luca Hospital, IRCCS Istituto Auxologico Italiano, Milan, Italy

Correspondence: Professor GS Stergiou, Hypertension Center, STRIDE Hellas-7, Third University Department of Medicine, Sotiria Hospital, 152 Mesogion Avenue, Athens 11527, Greece.

E-mail: gstergi@med.uoa.gr

Received 18 August 2013; Received 22 November 2013; accepted 27 November 2013; published online 20 February 2014 


\section{MATERIALS AND METHODS}

A systematic literature search was performed by two investigators (AN and AK) independently at PubMed database up to June 2013 using the keywords 'home', 'blood pressure' and 'variability'. Disagreements were discussed with senior author. Additional articles were searched from the reference lists of identified articles.

Studies eligible for review were those presenting original data from crosssectional or longitudinal studies in adults and examining day-by-day HBPV in terms of the following issues: (i) methodologies applied to evaluate and quantify the HBPV, (ii) relationship of HBPV with indices of preclinical target organ damage, (iii) prognostic value of HBPV in terms of cardiovascular morbidity and mortality, (iv) factors associated with HBPV and (v) effects of antihypertensive drug treatment on HBPV.

\section{RESULTS}

\section{HBPV evidence overview}

The overall search identified 190 potentially relevant articles. Twentytwo articles reported data from original studies and were included in the review (Figure 1). ${ }^{6,10-30}$ Fifteen $(68 \%)$ of these publications are derived from studies conducted in Japan. ${ }^{6,10-11,14-20,22-25,30}$ Five $^{6,10-13}$ studies investigated the prognostic relevance of HBPV, $6^{14-19}$ its association with indices of target organ damage (cardiac, arterial and renal), $13^{11,13,15,20-29}$ factors affecting HBPV and $8^{11,13,15,18,20,23,24,30}$ the effects of antihypertensive drug treatment on HBPV (some provided data on more than one of these issues).

In terms of design, most of the studies were cross-sectional, ${ }^{14,15-17,20-29}$ some had several months follow-up ${ }^{18,19,30}$ and few had almost 10 -year or longer follow-up. ${ }^{6,10-13}$ The study samples ranged from 26 to 2944 individuals and either included subjects with hypertension, diabetes, nephropathy or were drawn from general population.

There was wide diversity among the studies in the protocol used for HBP evaluation, in terms of (i) the time of the day (morning

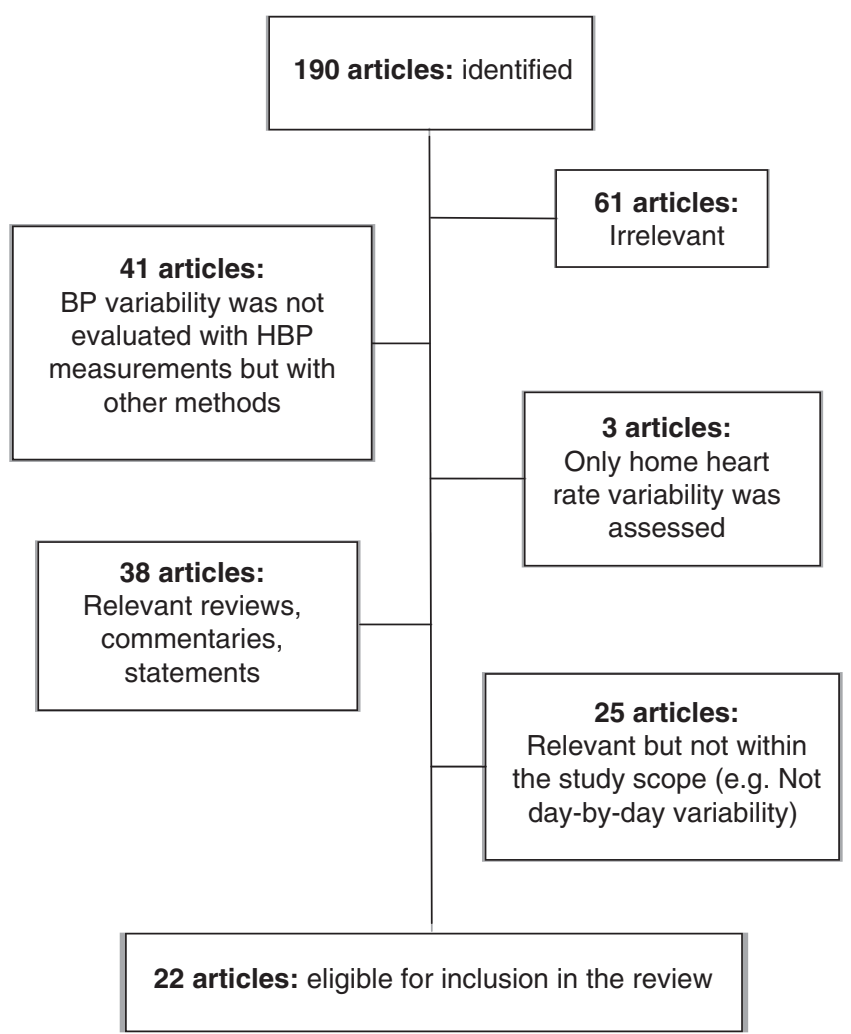

Figure 1 Flowchart of process for selection of articles. BP, blood pressure; HBP, home BP. measurements only, average of morning and evening measurements, and morning and evening measurements analyzed separately), (ii) the number of HBP readings taken per occasion (range from 1 to 5 ) and (iii) the number of HBP monitoring days (range from 2 to 26).

In regard to the methodology applied to evaluate and quantify the $\mathrm{HBPV}$, again there is large diversity among studies in the parameters used, including standard deviation (SD) and/or coefficient of variation $(\mathrm{CV})$ of all ${ }^{14,16-19,22-25,27-30}$ HBPs, or of morning HBPs, ${ }^{6,10,20}$ or SD of morning or evening HBP readings of a single occasion ${ }^{15}$ and SD of morning minus evening HBP difference, ${ }^{12,21,26}$ day-by-day HBPV (morning and evening), ${ }^{12,21,26,27}$ and first-second HBP measurement difference per occasion, ${ }^{12,21,26}$ or average real variability (ARV), ${ }^{11,13,19}$ variability independent of mean (VIM), ${ }^{11,13}$ maximum minus minimum HBP difference $(\mathrm{MMD})^{11,13}$ and maximum BP value ${ }^{14,18}$ which reflects the BP instability.

\section{Prognostic value of HBPM}

Five relevant articles were identified based on general population samples (Table 1). ${ }^{6,10-13}$ Three papers reported data from the same study in Japan (Ohasama). ${ }^{6,10-11}$ In the Ohasama study, high day-byday HBPV was associated with increased total, cardiovascular and stroke mortality, independently of the average HBP and other cardiovascular risk factors. ${ }^{6}$ Systolic HBPV was associated with cerebral infraction in ever, but not in never smokers. ${ }^{10}$ Morning VIM and ARV, independent of BP level, predicted total and cardiovascular mortality in all of the participants. ${ }^{11}$ However, being treated with BP lowering drugs undermined the predictive value of morning VIM in terms of total mortality, and in untreated participants only morning VIM predicted total mortality and only evening VIM predicted cardiovascular mortality. ${ }^{11}$ None of the new HBPV indices predicted stroke incidence and for all or cause-specific fatal combined with nonfatal outcomes the incremental predictive value of VIM, MMD and ARV over and beyond the average HBP level was minimal. ${ }^{11}$ It should be mentioned, however, that the Ohasama study included residents from a Japanese rural community, a population quite different from Western populations in terms of hypertension-related cardiovascular complications. Moreover, HBPV was calculated using single measurement readings obtained in a median period of 26 days, which is a different schedule than in European studies. In the Finn-Home study, where duplicate HBP readings were taken twice daily for 7 consecutive days in a random population sample of 1866 Finnish subjects, HBPV again predicted cardiovascular events and total mortality, and increased morning HBPV was an independent predictor of cardiovascular events. ${ }^{12}$ Another study in 2944 subjects in Belgium with 12-year follow-up failed to show predictive ability of novel indices of HBPV for cardiovascular mortality and morbidity. ${ }^{13}$ However, this was not a typical HBP monitoring study, because home measurements were taken by nurses who visited the participants' homes, and thus its results cannot be considered when focusing on HBPV. The latter study has additional drawbacks due to limited number of HBP readings (10 readings obtained in two home visits $2-4$ weeks apart) and the potential of observer bias and intra- and interobserver variability (auscultatory measurements using mercury sphygmomanometers). ${ }^{13}$

\section{Association of HBPV with target organ damage}

Six relevant studies were identified: five based on cross-sectional data analyses and one with follow-up data (Table 2). ${ }^{14-19}$ One crosssectional study in 356 untreated hypertensives who were instructed to take triplicate HBP measurements at 15-min intervals in the morning 
Table 1 Studies assessing the prognostic value of home blood pressure variability

\begin{tabular}{|c|c|c|c|c|c|c|}
\hline Study & Population (n) & $\begin{array}{l}\text { Follow-up } \\
\text { (years) }\end{array}$ & $\begin{array}{l}\text { HBP } \\
\text { (time/n/days) }\end{array}$ & HBPV measure & End points & Main findings \\
\hline $\begin{array}{l}\text { Kikuya et al. } \\
\text { (Ohasama) }^{6}\end{array}$ & General 2455 & 11.9 & $\mathrm{~m} / 1 / 26$ & $\mathrm{SD}, \mathrm{CV}$ & $\begin{array}{l}\text { Mortality total, CVD, } \\
\text { stroke, non-CVD, } \\
\text { cardiac }\end{array}$ & $\begin{array}{l}\text { Day/day S/D BPV independently associated with } \uparrow \text { Total, CVD, } \\
\text { stroke mortality (not cardiac) }\end{array}$ \\
\hline 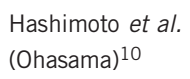 & $\begin{array}{l}\text { Men without } \\
\text { stroke } 902\end{array}$ & 13.1 & $\mathrm{~m} / 1 / 26$ & SD & $\begin{array}{l}\text { stroke according to } \\
\text { smoking status }\end{array}$ & $\begin{array}{l}\text { S-BPV associated with cerebral infarction in ever, not in never } \\
\text { smokers }\end{array}$ \\
\hline $\begin{array}{l}\text { Johansson et al. } \\
(\text { Finn-Home })^{12}\end{array}$ & General 1866 & 7.8 & $\mathrm{~m} \& \mathrm{e} / 2 / 7$ & $\begin{array}{l}\text { SD m-e, day/day } \\
\text { (m\&e), 1st-2nd }\end{array}$ & CVD, total mortality & $\begin{array}{l}\text { BPV } m-e, m \text { day/day independent predictors of CVD events. SBPV } \\
m-e, m \text { day/day, } 1 \text { st-2nd predicted total mortality }\end{array}$ \\
\hline
\end{tabular}

Abbreviations: ARV, average real variability; BP, blood pressure; BPV, BP variability; CV, coefficient of variation; CVD, cardiovascular disease; day/day, day-by-day; e, evening; HBP, home BP; HBPV, home BPV; m, morning; MMD, difference between maximum and minimum BP; n, number; S, systolic; SD, standard deviation; VIM, variability independent of mean; $\neq$, differing.

Table 2 Association of home blood pressure variability with target organ damage

\begin{tabular}{|c|c|c|c|c|c|c|}
\hline Study & Population (n) & Follow-up (years) & HBP (time/n/days) & HBPV measure & End points & Main findings \\
\hline Matsui et al. ${ }^{14}$ & 356 HTN untreated & Cross-sectional & $\mathrm{m} \& \mathrm{e} / 3 / 14$ & SD, Max & IMT & $\begin{array}{l}\text { Day/day S-BPV independently associated with } \\
\text { LVMI. } \\
\text { Max SBP independently associated with LVMI. } \\
\text { Day/day S-BPV not associated with IMT. } \\
\text { Max SBP independently associated with IMT }\end{array}$ \\
\hline Fukui et al. ${ }^{15}$ & 332 DM2 & Cross-sectional & $\mathrm{m} \& \mathrm{e} / 3 / 14$ & $\mathrm{SD} \mathrm{m}$ or $\mathrm{e}$ & PWV & $\begin{array}{l}\text { m S-SD (single occasion) independently } \\
\text { associated with PWV }\end{array}$ \\
\hline Okada et al. ${ }^{19}$ & 135 CKD 3-5 & 3 & $\mathrm{~m} \& \mathrm{e} / 1 / 7$ & $\mathrm{SD}, \mathrm{CV}, \mathrm{ARV}$ & CKD progression & No correlation with eGFR change or renal events \\
\hline Nishimura et al. ${ }^{17}$ & $268 \mathrm{DM} 2+\mathrm{MAU}$ & 3 baseline data & $\mathrm{m} \& \mathrm{e} / 1 / 7$ & SD & eGFR & Low eGFR independently correlated with S-SD \\
\hline Fukui et al. ${ }^{15}$ & 332 DM2 & Cross-sectional & $\mathrm{m \& e} / 3 / 14$ & $\mathrm{SD} \mathrm{m}$ or $\mathrm{e}$ & Proteinuria & $\begin{array}{l}\mathrm{m} \text { S-SD (single occasion) higher in patients with } \\
\text { proteinuria }\end{array}$ \\
\hline Ushigome et al. ${ }^{16}$ & 858 DM2 & Cross-sectional & m\&e/ 3/14 & CV & Proteinuria & $\begin{array}{l}\uparrow S-C V \text { in patients with proteinuria. } \mathrm{CV} \text { of } \mathrm{m} \text { SBP, } \\
\mathrm{m} \mathrm{DBP} \text {, e SBP independent predictors of UAE }\end{array}$ \\
\hline Hoshide et al. ${ }^{18}$ & $310 \mathrm{HTN}$ & 0.5 baseline data & $\mathrm{m} \& \mathrm{e} / 3 / 7$ & SD, Max & UAE & S-SD and max SBP associated with UAE \\
\hline Matsui et al. ${ }^{14}$ & 356 HTN untreated & Cross-sectional & $\mathrm{m} \& \mathrm{e} / 3 / 14$ & SD, Max & Ur Alb/Cr & $\begin{array}{l}\text { Day/day S-BPV not associated with Ur Alb/Cr. } \\
\text { Max SBP correlated with Ur Alb/Cr in all }\end{array}$ \\
\hline
\end{tabular}

Abbreviations: ARV, average real variability; BP, blood pressure; BPV, BP variability; CKD 3-5, chronic kidney disease stage 3-5; CV, coefficient of variation; DM2, diabetes mellitus type-2; e, evening; eGFR, estimated glomerular filtration rate; HBP, home BP; HBPV, home BPV; HTN, hypertensives; IMT, carotid intima-media thickness; LVMI, left ventricular mass index; m, morning; MAU, microalbuminuria; Max: maximum; n, number; PWV, pulse wave velocity; S, systolic; SD, standard deviation; UAE, urinary albumin excretion; Ur Alb/Cr, urinary albumin/creatinine ratio; $\uparrow$, elevated.

and the evening for 14 consecutive days, reported independent association of systolic HBPV and maximum systolic HBP with left ventricular mass index. ${ }^{14}$ Regarding to arterial damage, only maximum systolic HBP was shown to be independently associated with carotid intima-media thickness. ${ }^{14}$ The same study failed to show an association of HBPV with urinary albumin/creatinine ratio, yet the latter was independently associated with maximum systolic HBP. ${ }^{14}$ However, the use of maximum systolic HBP of 14-day HBP monitoring as a measure of $\mathrm{BP}$ variability raises concerns about its reproducibility and its adequacy to reflect short- or long-term BP variability. ${ }^{14} \mathrm{~A}$ study in 332 diabetic subjects showed that morning systolic HBPV on one occasion was higher in patients with proteinuria, and was independently, yet weakly, associated with pulse wave velocity. ${ }^{15}$ However, aiming to improve patients' compliance to the measurement procedure, this study obtained home readings at 15-s intervals. Another study in 858 type 2 diabetics demonstrated an association of HBPV with proteinuria, independent of other known risk factors. ${ }^{16}$ Finally, one study reported an independent association of low estimated glomerular filtration rate with systolic BP variability in 268 diabetics with microalbuminuria, ${ }^{17}$ whereas another paper in 310 hypertensives showed systolic BP variability and maximum systolic BP to be associated with urinary albumin excretion. ${ }^{18} \mathrm{~A}$ single study with 3 -year follow-up in 135 patients with nephropathy failed to show a significant association of HBPV with the progression of chronic kidney disease. ${ }^{19}$ However, it should be mentioned that the aforementioned study included single $\mathrm{BP}$ readings per occasion and did not use uniform devices for HBP monitoring. In addition, the investigators reported that in a 
considerable proportion of the participants, treatment was modified during the follow-up aiming to achieve a BP control. ${ }^{19}$ Thus, the BP lowering effect and the action of different antihypertensive drugs might have largely influenced the change in HBPV and estimated glomerular filtration rate. ${ }^{19}$

\section{Factors associated with HBPV}

Thirteen articles investigated factors associated with HBPV (Table 3). ${ }^{11,13,15,20-29}$ Advanced age, ${ }^{13,15,20-23,29}$ female gender, ${ }^{11,20-22,24-25}$ elevated mean $\mathrm{BP},{ }^{13,15,20-22}$ low body mass index, ${ }^{13,20}$ low heart rate, ${ }^{15,20,22,24}$ high heart rate variability, ${ }^{20,22,24}$ excessive alcohol intake, ${ }^{21-22}$ smoking, ${ }^{25}$ history of peripheral artery disease, ${ }^{13}$ cardiovascular disease, ${ }^{21}$ diabetes mellitus, ${ }^{21}$ diabetic nephropathy, ${ }^{24}$ pulse wave velocity, ${ }^{15}$ sedentary lifestyle, ${ }^{22}$ treated hypertension ${ }^{11,23}$ and treatment with beta-blockers, ${ }^{13,15}$ all have been associated with increased HBPV. HBPV appeared to be higher in the evening than in the morning. ${ }^{23-24}$ In a single study, HBPV was correlated with selfreported insomnia and sleep duration. ${ }^{26}$ A population study in 1701 elderly subjects showed that HBPV was similar in masked and sustained hypertensives and higher than in normotensives and white-coat hypertensives. ${ }^{27}$ Moreover, a study in 26 borderline hypertensives failed to correlate HBPV with personality/behavioral variables such as anxiety and anger. ${ }^{28}$ Finally, another study in a random population sample from Belgium demonstrated that diastolic $\mathrm{BP}$ variability is inversely correlated with self-rated physical activity in men, and that women living in working class area presents lower systolic BP variability. ${ }^{29}$

\section{Effects of antihypertensive treatment on HBPV}

Six cross-sectional studies reported data on the effect of drug treatment of HBPV (Table 4). Baseline evaluation in the Ohasama study revealed that HBPV was higher in treated than in untreated hypertensives. ${ }^{11,23}$ One study in diabetics and another in general population reported that BP variability was greater in those receiving beta-blockers. ${ }^{13,15}$ Other studies showed that treatment with alphablocker seemed to be related with lower $\mathrm{HBPV},{ }^{15}$ whereas treatment with an angiotensin II receptor blocker (ARB) and not with a calcium channel blocker (CCB) was associated with higher systolic BP variability in patients treated for $<1$ year. ${ }^{20}$ Short duration of treatment ${ }^{20}$ and increased number of antihypertensive drugs ${ }^{24}$ were associated with greater HBPV.

Two longitudinal studies investigated the effect of drug treatment of HBPV. The combination of an ARB with a CCB was found to be more effective in lowering systolic HBPV than the ARB/thiazide combination. ${ }^{30}$ Furthermore, the pulse wave velocity change induced by the ARB/CCB treatment ( 6 months) was independently associated with the change in systolic HBPV. ${ }^{30}$ However, in another study, based on a post hoc analysis of data from a small population sample, treatment-induced change in urinary albumin excretion (6 months) was not associated with that of systolic HBPV. Nevertheless, the follow-up period was too short to demonstrate the impact of $\mathrm{BP}$ variability decline on organ damage evolution.

\section{DISCUSSION}

There is an increasing interest and accumulating evidence on HBPV, with the majority of the studies performed in Japan and published in

Table 3 Factors associated with home blood pressure variability (cross-sectional analyses)

\begin{tabular}{|c|c|c|c|c|}
\hline Study & Population (n) & HBP (time/n/days) & HBPV measure & Main findings \\
\hline $\begin{array}{l}\text { Asayama et al. } \\
\text { (Ohasama) }^{11}\end{array}$ & General 2421 & $\mathrm{m \& e} / 1 / 26$ & VIM, MMD, ARV & $\begin{array}{l}\uparrow \mathrm{BPV} \text { in treated vs. untreated. Morning, not evening CV, VIM, MMD } \\
\uparrow \text { in females }\end{array}$ \\
\hline Fukui et al. ${ }^{15}$ & DM2 332 & $\mathrm{~m} \& \mathrm{e} / 3 / 14$ & $\mathrm{SD} \mathrm{m}$ or e & $\begin{array}{l}\text { Age, average m S-BP, HR, PWV correlated with SD of m SD (single } \\
\text { occasion). Age, average e S-BP, PWV correlated with SD of e S-SD }\end{array}$ \\
\hline Schutte et al. ${ }^{13}$ & General 2944 & $\begin{array}{l}\neq / 5 / 2 \text { visits }(2-4 \text { weeks; } \\
\text { nurses) }\end{array}$ & VIM, MMD,ARV & $\uparrow$ S-BPV: Males, older age, $\uparrow$ S-BP, $\downarrow$ BMI, PAD history, $\beta$-blocker use \\
\hline Ishikura et al. ${ }^{20}$ & HTN treated 1933 & $\mathrm{~m} / 1 / 14$ & $\mathrm{SD}, \mathrm{CV}$ & $\uparrow$ BPV: Females, Age, BP, HRV. $\downarrow$ BPV: HR, BMI, treatment duration \\
\hline $\begin{array}{l}\text { Johansson et al. } \\
\text { (Finn-Home) }^{26}\end{array}$ & General 1908 & $\mathrm{~m} \& \mathrm{e} / 2 / 7$ & $\begin{array}{l}\text { SD m-e, day/day (m\&e), } \\
\text { 1st-2nd }\end{array}$ & $\begin{array}{l}\uparrow \text { BPV: Insomnia. } \uparrow \text { BPV: Insomnia and short sleep duration. } \uparrow S \text { m-e, } \\
\text { day/day, m day/day: long sleepers. S m, D day/day: short sleepers }\end{array}$ \\
\hline $\begin{array}{l}\text { Johansson et al. } \\
\text { (Finn-Home) }\end{array}$ & General 1908 & $\mathrm{~m} \& \mathrm{e} / 2 / 7$ & $\begin{array}{l}\text { SD m-e, day/day (m\&e), } \\
1 \text { st-2nd }\end{array}$ & $\begin{array}{l}\uparrow \mathrm{m}-\mathrm{e} \text { BPV: Age, CVD, DM, high BPV. } \uparrow \mathrm{BPV}: \text { Age, } \uparrow \text { Alcohol, } \uparrow \mathrm{BP}, \\
\uparrow 1 \text { st-2nd BPV: Age, female, CVD, } \uparrow \mathrm{BP}\end{array}$ \\
\hline $\begin{array}{l}\text { Kato et al. } \\
(\text { Ohasama })^{22}\end{array}$ & General 1215 & $\mathrm{~m} \& \mathrm{e} / 1 / 26$ & $\mathrm{SD}, \mathrm{CV}$ & $\begin{array}{l}\uparrow \text { BPV: Age, Females, } \uparrow \text { BP, low HR, elevated HRV. } \uparrow \text { e BPV: Alcohol } \\
\text { intake; Sedentary lifestyle }\end{array}$ \\
\hline $\begin{array}{l}\text { Imai et al. } \\
\text { (Ohasama) }\end{array}$ & General 1207 & $\mathrm{~m} \& \mathrm{e} / 1 / 26$ & SD & $\uparrow$ BPV: evening than morning; Treated than untreated; Age \\
\hline Okada et al. ${ }^{24}$ & CKD 368 & $\mathrm{~m} \& \mathrm{e} / 1 / 7$ & $\mathrm{CV}$ & $\begin{array}{l}\uparrow \mathrm{m} \text { S-CV: Females, diabetic nephropathy, number of anti-HTN } \\
\text { drugs, } \uparrow \mathrm{HR}, \uparrow \mathrm{HRV}\end{array}$ \\
\hline Kawabe et al. ${ }^{25}$ & $\begin{array}{l}\text { HTN from a company } \\
605\end{array}$ & $\mathrm{~m} \& \mathrm{e} / 3 / 7$ & $\mathrm{SD}, \mathrm{CV}$ & $\uparrow \mathrm{m}$ S-CV: Smokers, Females \\
\hline Cacciolati et al. ${ }^{27}$ & Elderly 1701 & $\mathrm{~m} \& \mathrm{e} / 3 / 3$ & $7 \neq$ indexes & $\begin{array}{l}\uparrow \text { BPV: sustained and masked HTN vs. Normotension \& White-coat } \\
\text { HTN (treated and untreated) }\end{array}$ \\
\hline Schneider et al. ${ }^{28}$ & Borderline HTN 26 & $\mathrm{~m} \& \mathrm{e} / 1 / 7$ & $\mathrm{SD}$ & $\begin{array}{l}\text { BPV not increased in the high HBP group and not predicted by any of } \\
\text { the psychometric factors (anger, anxiety) }\end{array}$ \\
\hline Staessen et al. ${ }^{29}$ & General 784 & $\neq / 5 / 2$ visits (nurses) & $\mathrm{SD}, \mathrm{CV}$ & $\begin{array}{l}\text { BPV increases with advancing age. Men: D-BPV inversely correlated } \\
\text { with self-rated physical activity. Women: } \downarrow \text { S-BPV when living in a } \\
\text { working class area }\end{array}$ \\
\hline
\end{tabular}

Abbreviations: ARV, average real variability; BMI, body mass index. BP, blood pressure; BPV, BP variability; CKD, chronic kidney disease; CV, coefficient of variation; CVD, cardiovascular disease; $\mathrm{D}$, diastolic; day/day, day-by-day; DM2, diabetes mellitus type-2; HBP, home BP; HBPV, home BPV; HTN, hypertensives; HR, heart rate; HRV, HR variability; MMD, difference between maximum and minimum BP; n, number; PAD, peripheral artery disease; PWV, pulse wave velocity; S, systolic; SD, standard deviation; VIM, variability independent of mean; $\uparrow$, elevated; $\downarrow$, decreased; $\neq$, differing. 
Table 4 Effects of antihypertensive treatment on home blood pressure variability

\begin{tabular}{|c|c|c|c|c|c|}
\hline Study & Population (n) & $\begin{array}{l}\text { Duration } \\
\text { (years) }\end{array}$ & HBP (time/n/days) & $\begin{array}{l}\mathrm{HBPV} \\
\text { measure }\end{array}$ & Main findings \\
\hline $\begin{array}{l}\text { Imai et al. } \\
\text { (Ohasama) }^{23}\end{array}$ & $\begin{array}{l}\text { General } \\
1207\end{array}$ & Cross-sectional & $\mathrm{m} \& \mathrm{e} / 1 / 26$ & SD & BPV: treated > untreated \\
\hline $\begin{array}{l}\text { Asayama et al. } \\
\text { (Ohasama) }^{11}\end{array}$ & $\begin{array}{l}\text { General } \\
2421\end{array}$ & $\begin{array}{l}12 \\
\text { Baseline data }\end{array}$ & $\mathrm{m} \& \mathrm{e} / 1 / 26$ & $\begin{array}{l}\text { VIM, } \\
\text { MMD, ARV }\end{array}$ & BPV: treated > untreated \\
\hline Schutte et al. ${ }^{13}$ & $\begin{array}{l}\text { General } \\
2944\end{array}$ & $\begin{array}{l}12 \\
\text { Baseline data }\end{array}$ & f/5/2 visits (2-4 weeks; nurses) & $\begin{array}{l}\text { VIM, } \\
\text { MMD, ARV }\end{array}$ & Treatment with beta-blocker correlates with S-BPV \\
\hline Fukui et al. ${ }^{15}$ & $\begin{array}{l}\text { DM } 2 \\
332\end{array}$ & Cross-sectional & m\&e/3/14 & $\mathrm{SD} \mathrm{m}$ or $\mathrm{e}$ & $\begin{array}{l}\text { m or e S-SD (single occasion) lower with alpha-blockers than } \\
\text { without. e S-SD higher with beta-blockers than without }\end{array}$ \\
\hline Ishikura et al. ${ }^{20}$ & $\begin{array}{l}\text { HTN treated } \\
1933\end{array}$ & Cross-sectional & $\mathrm{m} / 1 / 14$ & $\mathrm{SD}, \mathrm{CV}$ & $\begin{array}{l}\text { Not on amlodipine and on ARB associated with } \uparrow \text { S-BPV } \\
\text { (only in patients treated for }<12 \text { months). Treatment } \\
\text { duration: negative association with BPV }\end{array}$ \\
\hline Matsui et al. ${ }^{30}$ & $\begin{array}{l}\text { HTN treated } \\
\text { olmesartan } 12 \\
\text { weeks } 207\end{array}$ & 0.5 & $m \& e / 3 / 5$ & SD & $\begin{array}{l}\text { S-SD decreased more with add-on CCB than TZD. CCB } \\
\text { group: PWV change associated with S-BPV change }\end{array}$ \\
\hline Hoshide et al. ${ }^{18}$ & $\begin{array}{l}\text { HTN } \\
310\end{array}$ & 0.5 & $\begin{array}{l}\text { m\&e/3/7, before and } 6 \text { months after } \\
\text { candesartan }+ \text { TZD }\end{array}$ & SD, max & $\begin{array}{l}\text { Treatment-induced } \downarrow \text { UAE not associated with that of SD or } \\
\max \text { SBP }\end{array}$ \\
\hline Okada et al. ${ }^{24}$ & $\begin{array}{l}\text { CKD } \\
368\end{array}$ & Cross-sectional & $\mathrm{m} \& \mathrm{e} / 1 / 7$ & $\mathrm{CV}$ & Number of anti-HTN drugs associated with $\uparrow \mathrm{m} \mathrm{S-CV}$ \\
\hline
\end{tabular}

the last 3 years. These studies have addressed most of the clinically relevant aspects of HBPV and showed encouraging preliminary results. However, at the present time, the available evidence is still limited and the large heterogeneity in BP measurement protocols and HBPV indices used in these studies does not allow a meta-analysis to be performed.

The current evidence suggests that HBPV: (i) appears to offer prognostic information independent of average HBP, (ii) has an independent role in the evolution and progression of preclinical cardiac, arterial and renal damage and (iii) is affected by age, gender, BP level, heart rate, antihypertensive treatment, antihypertensive drug class and other factors.

The outcome data relating HBPV with cardiovascular events' risk and total mortality (Table 1) are probably the most meaningful for clinical relevance, yet are essentially derived from two studies (Ohasama and Finn-Home), are based on post hoc analyses, and tested several different end points and indices of HBPV. A meticulous evaluation including novel indices of variability (VIM, MMD and $\mathrm{ARV}$ ) revealed minimal additional value beyond that of average HBP. ${ }^{11}$

The evidence in regard to the association of HBPV with preclinical organ damage (Table 2) is mainly based on cross-sectional analysis, yet most of these studies have been specifically designed for this purpose. Overall, these data suggest an independent association of HBPV with organ damage, with most of the studies assessing renal indices and scarce data on cardiac and arterial indices. In particular, Matsui et al. examining the relation of HBPV with all the above end points in 356 untreated hypertensives demonstrated that both day-byday systolic HBPV and maximum systolic HBP are independently associated with left ventricular mass index. ${ }^{14}$ However, only maximum systolic HBP was an independent determinant of carotid intima-media thickness, indicating that carotid atherosclerosis might be mainly influenced by transient BP fluctuations rather than by typical fluctuations of day-by-day BP variability. ${ }^{14}$ On the other hand, findings about renal damage coincided with those of Hoshide et al., ${ }^{18}$ suggesting a weak association of urinary albumin excretion with day-by-day HBPV and maximum systolic BP. The latter study, in a post hoc analysis of data from a small population sample, although showed a significant correlation between baseline urinary albumin excretion and HBPV, failed to show a reduction of normo- and microalbuminuria after treatment-induced reduction in HBPV. ${ }^{18}$ On the contrary, studies by Fukui et al. ${ }^{15}$ and Ushigome et al..$^{16}$ in diabetic subjects demonstrated a significant association between HBPV and proteinuria. The small effect of maximum systolic HBP on renal indices might be explained by the autoregulatory renal mechanisms that prevent transient BP fluctuations to be transmitted to glomerular capillary circulation and affect glomerular function. ${ }^{14}$ Regarding the conflicting findings in patients with normo- or microalbuminuria compared with those with proteinuria, it has been suggested that urinary albumin excretion in the range of normo- to microalbuminuria may not be a reliable index of renal damage and its progression. ${ }^{31}$ Okada et al. ${ }^{19}$ also reported the absence of association between HBPV and nephropathy progression in 135 patients with chronic kidney disease. However, it should be considered that chronic renal disease has been mainly associated with alterations in short-term BP variability, especially with elimination or inversion of circadian BP variation, which has been attributed to sympathetic hyperactivity (neurohormonal changes due to renal failure) ${ }^{32}$ and impaired aortic and carotid baroflexes (uremia-related increase in arterial calcification and stiffness). ${ }^{33,34}$ Thus, because $24 \mathrm{~h}$ ambulatory BP monitoring was not used, meaningful abnormalities in BP variability might have been missed. ${ }^{34}$

Undoubtedly, BP variability is a rather complex phenomenon. From a physiological point of view, it reflects the influences of increased sympathetic drive and reduced arterial and cardiopulmonary reflexes. ${ }^{35-37}$ Moreover, impaired arterial compliance, humoral factors (angiotensin II, bradykinin, endothelin-1, insulin and nitric oxide), blood viscosity, behavioral changes (physical activity, sleep, postural changes and so on), emotional factors and even climatic changes might contribute in the generation of BP fluctuations. ${ }^{35,38}$ 
More specifically, mid-term day-by-day HBPV might also be due to limited accuracy of self-measurements, the imperfect stability of BP control in treated patients due to improper titration/dosing of medication or poor patients' compliance with the prescribed regimen (dose omission, delay in drug intake and so on). ${ }^{35}$ Nevertheless, multiple other factors have been shown to affect HBPV in secondary analyses of relevant studies (Table 3). Some of them, such as age, gender, BP level, treatment status and heart rate have been consistent in several studies, which implies a true association. The impact of aging on $\mathrm{BP}$ variability is probably due to impaired baroreceptor sensitivity, a condition that promotes transient BP fluctuations due to exaggerated pressor response to mental and physical stimuli. ${ }^{22}$ Moreover, advanced age is accompanied by arterial stiffness, a condition of decreased arterial compliance that also attenuates baroreflex function and contributes to increased BP variability. ${ }^{22}$

The evidence on the effect of antihypertensive drugs on HBPV is rather limited (Table 4), yet the findings of a favorable effect of CCBs but not of beta-blockers is consistent with data for office and ambulatory BP variability, ${ }^{4}$ which implies common mechanisms influencing HBPV as for office and ambulatory BP variability. This was demonstrated by Rothwell et al. ${ }^{4}$ in the ASCOT-BPLA (Anglo-Scandinavian Cardiac Outcomes Trial Blood Pressure Lowering Arm) in high-risk hypertensives and also in the Medical Research Council trial in elderly hypertensives. It should be mentioned that these results are based on post hoc analyses on selective population samples and, due to methodological limitations, the ASCOT-BPLA analysis had to rely on interindividual BP variation that was arbitrarily used as surrogate measure of intraindividual BP variability. ${ }^{7}$ However, the similarity of these findings with those obtained by HBP measurements implies common mechanisms influencing HBPV as for office and ambulatory BP variability.

The favorable effects of CCBs, and particularly of amlodipine, on $\mathrm{BP}$ variability have been attributed to their vasodilating effects on peripheral muscular arteries that lead to decreased peripheral resistance and arterial stiffness with subsequent improvement of arterial baroflex sensitivity, as well as to the long duration of action (amlodipine). Moreover, there is evidence that amlodipine might lead to decreased BP variability by suppressing arterial stiffening via anti-inflammatory and antioxidant effects (Limit Occurrences of Thrombosis (CAMELOT) Study). ${ }^{20,39}$ The findings by Ishikura et al. ${ }^{20}$ reporting increased $\mathrm{HBPV}$ with of $\mathrm{ARB}$ use in patients treated for $<12$ months conflict with previous studies demonstrating antiatherogenic properties and suppression of sympathetic activity of this drug class. ${ }^{20,40-42}$ In addition, the different effects of CCBs and ARBs on HBPV during the first year of treatment was not apparent thereafter. ${ }^{20}$ This observation might indicate that prolonged antihypertensive therapy might stabilize BP variation, probably by reducing arterial stiffness. ${ }^{20}$ Interestingly, the effect of antihypertensive drugs on HBPV may be largely affected by the duration of treatment, with long-term treatment resulting in decreased HBPV irrespectively of the class of antihypertensive drugs used. ${ }^{20}$ On the other hand, in the studies of Schutte et al. ${ }^{13}$ and Fukui et al., ${ }^{15}$ the use of betablockers was associated with elevated HBPV. This finding might be attributed to vasoconstriction, increased peripheral resistance and reduced compliance of the elastic arteries. However, in the same population Fukui et al. ${ }^{15}$ found that alpha-blockers exhibit opposite effects on BP variability, which might be explained by the suppressing action of alpha-blockers on the autonomic nervous system activation. $^{15}$
The findings by Matsui et al. ${ }^{30}$ that the addition of a CCB instead of a thiazide in a treatment regimen with an inhibitor of the reninangiotensin system led to greater decrease of HBPV, whereas the ARB/ thiazide combination did not alter the magnitude of HBPV, may imply that the use of renin-angiotensin inhibitors may be related with increased BP variability whereas the use of thiazide with lower BP variability (yet higher than that of CCB). Another meaningful point is that plasma aldosterone concentration was reported to be increased only after treatment with the ARB/thiazide combination..$^{30,43}$ Taking into account that elevated aldosterone levels impair baroreceptor sensitivity in humans, ${ }^{44}$ this drug-induced aldosterone excess may explain why the ARB/thiazide group was associated with lesser decline in $\mathrm{HBPV}^{30}$

In the absence of direct comparisons of HBPV with office and ambulatory BP variability, it is not known whether there are important differences in the information provided by these measures, whether their predictive role is complementary, or whether one of them allows more accurate prediction of risk. Preliminary data suggest that there are differences in the levels of office, home and ambulatory BP variability and moderate correlation among them, yet there is fair agreement (60-70\%) among the three methods in detecting subjects with high BP variability defined as those at the highest SD quartile by each method. ${ }^{45}$ Moreover, the change in HBPV after one year of antihypertensive treatment appeared to be superior to that of office or ambulatory BP variability in predicting the treatment-induced change in left ventricular mass index or pulse wave velocity. ${ }^{46}$

Although these data require confirmation and more research is needed, from the practical point of view HBPV appears to be the most feasible method for the evaluation of variability, given the wide availability of HBP monitors and the good acceptance of this method by hypertensive patients for long-term use. ${ }^{9}$ Regarding office BP variability assessed in repeated visits, although it was proved to be successful in the context of outcome trials ${ }^{3,4}$ or surveys, ${ }^{5}$ it might be impractical for routine clinical use due to poorly standardized office measurements and to the long time required for multiple visits. Regarding the 24-h ambulatory BP variability, in a retrospective analysis of the ASCOT-BPLA study it appeared to be inferior to the visit-to-visit office BP variability in terms of their impact on vascular events, ${ }^{4}$ although the results of many observational studies, some of which including follow-up data, have emphasized that 24-h ambulatory BP variability is significantly associated with organ damage and cardiovascular events over and above the impact of increased average BP levels. ${ }^{47}$ An analysis of the International Database on Ambulatory Blood Pressure in Relation to Cardiovascular Outcome (IDACO) including 8938 subjects, showed that 24-h ambulatory BP variability, although significantly predictive of cardiovascular risk, did not provide a significant contribution to risk stratification over and beyond average ambulatory $\mathrm{BP},{ }^{2}$ but the results of such analysis might have been biased by different methodological features of ambulatory BP monitoring performed in the different countries included. In spite of the interesting information provided by ambulatory BP monitoring, however, it has to be acknowledged that this approach is still not widely available and may not be suitable for repeated use in the long-term follow-up.

Even if it is decided that HBPV is the optimal measurement method for the evaluation of BP variability between days and/or visits, several fundamental research questions need to be addressed before this approach can be proposed for clinical application. Studies are needed to show (i) which index more accurately represents the impact of HBPV on the cardiovascular system, (ii) which is the 
optimal HBP monitoring schedule that gives a reproducible and reliable assessment of HBPV, (iii) which threshold defines increased HBPV in terms of its association with organ damage and cardiovascular disease and (iv) whether treatment-induced changes in HBPV affect target organ damage and cardiovascular event risk. Until these research questions are adequately addressed and a practical and efficient approach for applying this challenging concept in clinical practice is agreed, HBPV assessment should largely remain a research issue with little practical value for individual patients.

\section{CONFLICT OF INTEREST}

The authors declare no conflict of interest.

1 Parati G, Pomidossi G, Albini F, Malaspina D, Mancia G. Relationship of 24-hour blood pressure mean and variability to severity of target-organ damage in hypertension. J Hypertens 1987; 5: 93-98.

2 Hansen TW, Thijs L, Li Y, Boggia J, Kikuya M, Björklund-Bodegård K, Richart T, Ohkubo T, Jeppesen J, Torp-Pedersen C, Dolan E, Kuznetsova T, Stolarz-Skrzypek K, Tikhonoff V, Malyutina S, Casiglia E, Nikitin Y, Lind L, Sandoya E, Kawecka-Jaszcz K, Imai Y, Wang J, Ibsen H, O'Brien E, Staessen JA. International Database on Ambulatory Blood Pressure in Relation to Cardiovascular Outcomes Investigators. Prognostic value of reading-to-reading blood pressure variability over 24 hours in 8938 subjects from 11 populations. Hypertension 2010; 55: 1049-1057.

3 Rothwell PM, Howard SC, Dolan E, O'Brien E, Dobson JE, Dahlöf B, Sever PS, Poulter NR. Prognostic significance of visit-to-visit variability, maximum systolic blood pressure, and episodic hypertension. Lancet 2010; 375: 895-905.

4 Rothwell PM, Howard SC, Dolan E, O'Brien E, Dobson JE, Dahlöf B, Poulter NR, Sever PSASCOT-BPLA and MRC Trial Investigators. Effects of beta blockers and calcium-channel blockers on within-individual variability in blood pressure and risk of stroke. Lancet Neurol 2010; 9: 469-480.

5 Muntner P, Shimbo D, Tonelli M, Reynolds K, Arnett DK, Oparil S. The relationship between visit-to-visit variability in systolic blood pressure and all-cause mortality in the general population: findings from NHANES III, 1988 to 1994. Hypertension 2011; 57: 160-166.

6 Kikuya M, Ohkubo T, Metoki H, Asayama K, Hara A, Obara T, Inoue R, Hoshi H, Hashimoto J, Totsune K, Satoh H, Imai Y. Day-by-day variability of blood pressure and heart rate at home as a novel predictor of prognosis: the Ohasama study. Hypertension 2008; 52: 1045-1050.

7 Stergiou GS, Parati G. How to best assess blood pressure? The ongoing debate on the clinical value of blood pressure average and variability. Hypertension 2011; 57: 1041-1042.

8 Parati G, Stergiou GS, Asmar R, Bilo G, de Leeuw P, Imai Y, Kario K, Lurbe E, Manolis A, Mengden T, O'Brien E, Ohkubo T, Padfield P, Palatini P, Pickering T, Redon J, Revera M, Ruilope LM, Shennan A, Staessen JA, Tisler A, Waeber B, Zanchetti A, Mancia GESH Working Group on Blood Pressure Monitoring. European Society of Hypertension guidelines for blood pressure monitoring at home: a summary report of the Second International Consensus Conference on Home Blood Pressure Monitoring. J Hypertens 2008; 26: 1505-1526.

9 Stergiou GS, Nasothimiou EG. Home monitoring is the optimal method for assessing blood pressure variability. Hypertens Res 2011; 34: 1246-1248.

10 Hashimoto T, Kikuya M, Ohkubo T, Satoh M, Metoki H, Inoue R, Asayama K, Kanno A Obara T, Hirose T, Hara A, Hoshi H, Totsune K, Satoh H, Sato H, Imai Y. Home blood pressure level, blood pressure variability, smoking, and stroke risk in Japanese men: the Ohasama study. Am J Hypertens 2012; 25: 883-891.

11 Asayama K, Kikuya M, Schutte R, Thijs L, Hosaka M, Satoh M, Hara A, Obara T, Inoue R, Metoki H, Hirose T, Ohkubo T, Staessen JA, Imai Y. Home blood pressure variability as cardiovascular risk factor in the population of Ohasama. Hypertension 2013; 61: 61-69.

12 Johansson JK, Niiranen TJ, Puukka PJ, Jula AM. Prognostic value of the variability in home-measured blood pressure and heart rate: the Finn-Home Study. Hypertension 2012; 59: 212-218.

13 Schutte R, Thijs L, Liu YP, Asayama K, Jin Y, Odili A, Gu YM, Kuznetsova T, Jacobs L, Staessen JA. Within-subject blood pressure level—not variability — predicts fatal and nonfatal outcomes in a general population. Hypertension 2012; 60: 1138-1147.

14 Matsui Y, Ishikawa J, Eguchi K, Shibasaki S, Shimada K, Kario K. Maximum value of home blood pressure: a novel indicator of target organ damage in hypertension. Hypertension 2011; 57: 1087-1093.

15 Fukui M, Ushigome E, Tanaka M, Hamaguchi M, Tanaka T, Atsuta H, Ohnishi M, Oda Y, Hasegawa G, Nakamura N. Home blood pressure variability on one occasion is a novel factor associated with arterial stiffness in patients with type 2 diabetes. Hypertens Res 2013; 36: 219-225.

16 Ushigome E, Fukui M, Hamaguchi M, Senmaru T, Sakabe K, Tanaka M, Yamazaki M, Hasegawa G, Nakamura N. The coefficient variation of home blood pressure is a novel factor associated with macroalbuminuria in type 2 diabetes mellitus. Hypertens Res 2011; 34: 1271-1275.
17 Nishimura M, Kato Y, Tanaka T, Todo R, Tone A, Yamada K, Ootani S, Kawabe Y, Yoshizumi H, Hoshiyama Y. Significance of estimating the glomerular filtration rate for the management of hypertension in type 2 diabetes with microalbuminuria. Hypertens Res 2013; 36: 705-710.

18 Hoshide S, Yano Y, Shimizu M, Eguchi K, Ishikawa J, Kario K. Is home blood pressure variability itself an interventional target beyond lowering mean home blood pressure during anti-hypertensive treatment? Hypertens Res 2012; 35: 862-866.

19 Okada T, Matsumoto H, Nagaoka Y, Nakao T. Association of home blood pressure variability with progression of chronic kidney disease. Blood Press Monit 2012; 17: $1-7$

20 Ishikura K, Obara T, Kato T, Kikuya M, Shibamiya T, Shinki T, Ikeda U, Kobayashi Y, Metoki H, Mano N, Kuriyama S, Ohkubo T, Imai Y. J-HOME-Morning Study Group. Associations between day-by-day variability in blood pressure measured at home and antihypertensive drugs: the J-HOME-Morning study. Clin Exp Hypertens 2012; 34: 297-304.

21 Johansson JK, Niiranen TJ, Puukka PJ, Jula AM. Factors affecting the variability of home-measured blood pressure and heart rate: the Finn-home study. J Hypertens 2010; 28: 1836-1845.

22 Kato T, Kikuya M, Ohkubo T, Satoh M, Hara A, Obara T, Metoki H, Asayama K, Hirose T, Inoue R, Kanno A, Totsune K, Hoshi H, Satoh H, Imai Y. Factors associated with day-by-day variability of self-measured blood pressure at home: the Ohasama study. Am J Hypertens 2010; 23: 980-986.

23 Imai Y, Nishiyama A, Sekino M, Aihara A, Kikuya M, Ohkubo T, Matsubara M, Hozawa A, Tsuji I, Ito S, Satoh H, Nagai K, Hisamichi S. Characteristics of blood pressure measured at home in the morning and in the evening: the Ohasama study. J Hypertens 1999; 17: 889-898.

24 Okada T, Nakao T, Matsumoto H, Nagaoka Y, Tomaru R, Iwasawa H, Wada T. Day-by-day variability of home blood pressure in patients with chronic kidney disease. Nihon Jinzo Gakkai Shi 2008; 50: 588-596.

25 Kawabe H, Kanda T, Hirose H, Saito I. Variability of home blood pressure measurements between first and second measurements on one occasion, and factors related to variability. Clin Exp Hypertens 2012; 34: 237-242.

26 Johansson JK, Kronholm E, Jula AM. Variability in home-measured blood pressure and heart rate: associations with self-reported insomnia and sleep duration. J Hypertens 2011; 29: 1897-1905.

27 Cacciolati C, Tzourio C, Hanon O. Blood pressure variability in elderly persons with white-coat and masked hypertension compared to those with normotension and sustained hypertension. Am J Hypertens 2013; 26: 367-372.

28 Schneider RH, Egan BM, Johnson EH, Drobny H, Julius S. Anger and anxiety in borderline hypertension. Psychosom Med 1986; 48: 242-248.

29 Staessen JA, Fagard R, Amery A. Life style as a determinant of blood pressure in the general population. Am J Hypertens 1994; 7: 685-694.

30 Matsui Y, O’Rourke MF, Hoshide S, Ishikawa J, Shimada K, Kario K. Combined effect of angiotensin II receptor blocker and either a calcium channel blocker or diuretic on day-by-day variability of home blood pressure: the Japan Combined Treatment With Olmesartan and a Calcium-Channel Blocker Versus Olmesartan and Diuretics Randomized Efficacy Study. Hypertension 2012; 59: 1132-1138.

31 Tamura K, Shibuya K, Takeshita Y, Koide Y, Tokita Y, Umemura S. Questionable link between normo- to microalbuminuria and home-measured blood pressure variability in hypertension. Hypertens Res 2012; 35: 802-804.

32 Andersen KF, Enevoldsen LH. Sympathetic overactivity in uremia detected by 123I-MIBG scintigraphy. Clin Nucl Med 2008; 33: 790-791.

33 Covic A, Goldsmith DJ. Ambulatory blood pressure monitoring in nephrology: focus on BP variability. J Nephrol 1999; 12: 220-229.

34 Parati G, Ochoa JE, Bilo G. Blood pressure variability, cardiovascular risk, and risk for renal disease progression. Curr Hypertens Rep 2012; 14: 421-431.

35 Parati G, Juan EO, Lombardi C, Bilo G. Assessment and management of blood-pressure variability. Nat Rev Cardiol 2013; 10: 143-155.

36 Mancia G, Parati G, Pomidossi G, Casadei R, Di Rienzo M, Zanchetti A. Arterial baroreflexes and blood pressure and heart rate variabilities in humans. Hypertension 1986; 8: 147-153.

37 Conway J, Boon N, Davies C, Jones JV, Sleight P. Neural and humoral mechanisms involved in blood pressure variability. J Hypertens 1984; 2: 203-208.

38 Mancia G, Grassi G. Mechanisms and clinical implications of blood pressure variability. J Cardiovasc Pharmacol 2000; 35(7 Suppl 4), S15-S19.

39 Nissen SE, Tuzcu EM, Libby P, Thompson PD, Ghali M, Garza D, Berman L, Shi H, Buebendorf E, Topol EJCAMELOT Investigators. Effect of antihypertensive agents on cardiovascular events in patients with coronary disease and normal blood pressure: the CAMELOT study: a randomized controlled trial. J Am Med Assoc 2004; 292 : 2217-2225

40 Papademetriou V, Farsang C, Elmfeldt D, Hofman A, Lithell H, Olofsson B, Skoog I, Trenkwalder P, Zanchetti AStudy on Cognition and Prognosis in the Elderly study group. Stroke prevention with the angiotensin II type 1-receptor blocker candesartan in elderly patients with isolated systolic hypertension: the Study on Cognition and Prognosis in the Elderly (SCOPE). J Am Coll Cardiol 2004; 44: 1175-1180.

41 Kizer JR, Dahlöf B, Kjeldsen SE, Julius S, Beevers G, de Faire U, Fyhrquist F, Ibsen H, Kristianson K, Lederballe-Pedersen O, Lindholm LH, Nieminen MS, Omvik P, Oparil S, Wedel H, Wachtell K, Edelman JM, Snapinn SM, Harris KE, Devereux RB. Stroke reduction in hypertensive adults with cardiac hypertrophy randomized to losartan versus atenolol: the Losartan Intervention for Endpoint Reduction in Hypertension study. Hypertension 2005; 45: 46-52. 
42 Balt JC, Mathy MJ, Pfaffendorf M, van Zwieten PA. Sympathoinhibitory properties of various AT1 receptor antagonists. J Hypertens Supp/ 2002; 20: S3-S11.

43 Matsui Y, Eguchi K, O'Rourke MF, Ishikawa J, Shimada K, Kario K. Association between aldosterone induced by antihypertensive medication and arterial stiffness reduction: the J-CORE Study. Atherosclerosis 2011; 215 184-188.

44 Monahan KD, Leuenberger UA, Ray CA. Aldosterone impairs baroreflex sensitivity in healthy adults. Am J Physiol Heart Circ Physiol 2007; 292: H190-H197.
45 Nasothimiou EG, Karpettas N, Destounis A, Moyssakis I, Tzamouranis D, Stergiou GS Blood pressure variability assessed by clinic, home and ambulatory measurements. (Abstract). J Hypertens 2011; 29 (suppl. A), e448.

46 Karpettas N, Kollias A, Moissakis I, Roussias L, Achimastos A, Stergiou GS. Treatmentinduced changes in clinic, home and ambulatory blood pressure variability: prediction of changes in target organ damage. (Abstract). J Hypertens 2013; 31 (suppl. A), e38.

47 Parati G, Ochoa JE, Lombardi C, Bilo G. Assessment and management of blood pressure variability. Nat Rev Cardiol 2013; 10: 143-155. 